\title{
LA DEUDA PÚBLICA DE LOS MUNICIPIOS ARAGONESES EN LOS SIGLOS XIV Y XV ${ }^{1}$
}

\author{
PUBLIC DEBT IN ARAGONESE MUNICIPALITIES \\ IN THE 14th AND 15th CENTURIES
}

\author{
JUAN ABELLA SAMITIER \\ Universidad de Zaragoza
}

\begin{abstract}
Resumen: El objeto de este artículo es estudiar los orígenes de la deuda pública de los municipios aragoneses en el siglo XIV y su evolución en el siglo XV. En este sentido, se analiza especialmente la cronología de las principales emisiones, los cambios en los tipos de interés y las causas que obligaron a las ciudades y villas del reino a endeudarse.
\end{abstract}

Palabras clave: Reino de Aragón; Baja Edad Media; Deuda pública; Ciudades y villas; Monarquía; Cortes; Guerra.

\begin{abstract}
This article aims at studying the origin of public debt in Aragon in the 14th century and its development in the 15th century. Hence, the dire state of municipal finances, the reasons that led city and town councils to run into debt, cuts and rises in interest rates, and some the most important issues of public debt will be fully discussed and analysed.
\end{abstract}

Keywords: Kingdom of Aragon; Late Middle Ages; Public debt; City and town councils; Monarchy; Parliament; War.

\section{SUMARIO}

1. Introducción.- 2. Un nebuloso siglo XIV.- 3. Las emisiones de deuda pública en el siglo XV.- 4. Conclusiones.- 5. Apéndice.

\section{INTRODUCCIÓN}

El estudio de la deuda pública de los municipios aragoneses en la Baja Edad Media, pese a ser uno de los capítulos fundamentales en el devenir histórico de sus diferentes villas y ciudades en el pasado, ha sido un aspecto que no se ha abordado con la profusión y sistematicidad que en otros territorios de la Corona, singularmente Cataluña y Valencia ${ }^{2}$.

\footnotetext{
${ }^{1}$ Este texto fue presentado al Coloquio "Endeudamiento público, monarquías y ciudades en los reinos hispánicos (siglos XIV-XVII)", celebrado en Barcelona entre el 6 y el 8 de noviembre de 2008, bajo la coordinación del Prof. Dr. Manuel Sánchez Martínez.

${ }^{2}$ Sin ánimo de ser exhaustivos, de la abundante producción historiográfica sobre fiscalidad y deuda pública en Cataluña deben señalarse las siguientes obras: Manuel SÁNCHEZ MARTíNEZ, Pagar al rey en la Corona de Aragón durante el siglo XIV. Estudios sobre fiscalidad y finanzas reales y urbanas, Barcelona, CSIC, Institución Mila y Fontanals, 2003; Pere ORTI GoST, Renda i fiscalitat en una ciutat medieval: Barcelona, segles XII-XIV, Barcelona, CSIC, Institución Milá
} 
En efecto, el estudio en Aragón, ya no de la deuda pública en sí, sino de las haciendas locales desde una óptica global, se caracteriza por la relativa escasez de investigaciones y por el hecho de que éstas suelen presentar una cronología más bien tardía, en torno al siglo XV, y en muchas ocasiones bien avanzado éste. Ello se debe, en gran medida, a la propia disponibilidad de fuentes municipales de naturaleza financiera para esta época.

Así, para la capital del reino, la ciudad de Zaragoza, los libros de actos comunes comienzan a conservarse, y no de manera continua, a partir del año 1440, mientras que los cabreos o relaciones de propiedades concejiles lo hacen desde 1444. Igualmente se dispone de dos libros de mayordomía, uno muy temprano, del ejercicio 1373-74, y otro de $1456^{3}$. En cuanto a Huesca, su primer libro de actas conservado data de 1457, al que le siguen veintidós más que cubren, con lagunas, el periodo medieval; además, el concejo oscense posee varios libros de cuentas cuya cronología abarca de 1450 a $1492^{4}$.

Por otra parte, para la ciudad de Daroca se tienen veinticinco libros contables desde el año 1449 al $1500^{5}$. En Fraga, los libros de actas del concejo se inician en el Cuatrocientos, debiendo señalarse además que el archivo fragatino ha tenido la suerte de que se conserven un libro cabreo de rentas y pagos de la villa del año $1434 \mathrm{y}$, sobre todo, una serie de pergaminos de censales que comienza en el siglo $\mathrm{XIV}^{6}$.

Más desafortunadas en cuanto a la conservación de sus fondos municipales del Medioevo han resultado localidades de un rango poblacional menor, de entre 100 y 200 fuegos, como Sos, Sádaba y Uncastillo, ubicadas en la frontera con Navarra, cuyos archivos fueron destruidos en el transcurso

y Fontanals, 2000; Jordi MORELLÓ BAGET, Fiscalitat $i$ deute públic en dues viles del Camp de Tarragona. Reus $i$ Valls, segles XIV-XV, Barcelona, CSIC, Institución Milá y Fontanals, 2001 ; Pere VERDÉS PIJUAN, "Per co que la vila no vage a perdició". La gestió del deute públic en un municipi català (Cervera, 1387-1516), Barcelona, CSIC, Institución Milá y Fontanals, 2004. Para el reino de Valencia, véase Juan Vicente GARCíA MARSILLA, Vivir a crédito en la Valencia medieval. De los origenes del sistema censal al endeudamiento del municipio, Valencia, Universitat de València, 2002; Pau VICIANO NAVARRO, Fiscalitat i deute públic al País Valencià. L'administració de la vila de Borriana a mitjan segle XV, "Anuario de Estudios Medievales", 22 (1992), pp. 513-533. Sobre el reino de Mallorca, véase Pau CATEURA BENNASSER, El'rey burlado: deuda pública y fiscalidad en el reino de Mallorca (siglo XV), "Anuario de Estudios Medievales", 38 (2008), pp. 185-211. En cuanto al reino de Aragón, son de necesaria consulta los artículos de María Isabel FALCÓN PÉREZ, El sistema fiscal de los municipios aragoneses, en Manuel SÁNCHEZ MARTÍNEZ, Antoni FURIÓ DIEGO (ẹs.) "Actes del Col-loqui Corona, municipis i fiscalitat a la Baixa Edat Mitjana”, Lleida, Institut d'Estudis Ilerdencs, 1997 ‘ pp. 191218; Finanzas y fiscalidad de ciudades, villas y comunidades de aldeas aragonesas, en "Finanzas y fiscalidad municipal. V Congreso de Estudios Medievales ”, León, Fundación Sánchez Albornoz, 1997, pp. 241-273.

${ }^{3}$ Bonifacio PALACIOS MARTÍN; María Isabel FALCÓN PÉREZ, La hacienda municipal de Zaragoza a mediados del siglo XV (1440-1472), en Historia de la Hacienda Española. Homenaje a Garcia de Valdeavellano, Madrid, 1982, pp. 543-545.

${ }^{4}$ María Teresa IRANZO MUÑío, Élites políticas y gobierno urbano en Huesca en la Edad Media, Crónica, Estudios y documentos sobre Huesca, 2005, pp. 20-25.

${ }^{5}$ María Luz Rodrigo ESTEVAN, Poder y vida cotidiana en una ciudad bajomedieval: Daroca, 1400-1526, Zaragoza, Prensas Universitarias de Zaragoza (microformas), 1996, pp. 272-274.

${ }^{6}$ Antonio BERENGUER GALINDO, Censal mort. Historia de la deuda pública del Concejo de Fraga (siglos XIV-XVIII), Instituto de Estudios Altoaragoneses, Ayuntamiento de Fraga, 1998, pp. 16-20. 
de las Guerras de Sucesión y de la Independencia en los siglos XVIII y XIX. No obstante, la preservación de cerca de 300 pequeños protocolos notariales del siglo XV, de una marcada naturaleza rural, ha permitido rescatar múltiples noticias de carácter hacendístico con las que reconstruir, en parte, la evolución de las arcas locales de estas modestas villas ${ }^{7}$.

De esta manera, se puede concluir que los estudios sobre finanzas locales en Aragón han estado muy determinados por este carácter relativamente tardío de las fuentes conservadas y por el hecho de que la mayoría de investigaciones se han centrado en los archivos municipales, dejando en un segundo plano los notariales y sobre todo la rica documentación del Archivo de la Corona de Aragón ${ }^{8}$ que tanta luz podría aportar, especialmente para épocas como el siglo XIV donde escasean las fuentes locales.

El objetivo de este artículo consiste en fijar los principales hitos de la emisión de deuda pública en el reino de Aragón en la Baja Edad Media, en aspectos como la cronología, las diferentes modalidades crediticias contraídas por los consistorios y la evolución a lo largo del tiempo de sus tipos de interés. Igualmente, se pretende esclarecer las diversas causas que llevaron a los municipios a emprender una política económica que terminó en muchas ocasiones con la quiebra de sus finanzas.

\section{UN NEBULOSO SIGLO XIV}

A diferencia de Cataluña y de Valencia, donde minuciosas investigaciones han establecido con precisión la cronología de las primeras emisiones masivas de censales y de violarios y las circunstancias en las que se produjeron, en Aragón los orígenes de la deuda de sus municipios y su evolución a lo largo del siglo XIV permanecen ocultos entre nieblas.

No obstante, se dispone de referencias para algunas de las localidades más importantes del viejo reino, lo que puede esclarecer algo este oscuro panorama. Comenzaremos por la capital, la ciudad de Zaragoza, que, como el resto de poblaciones aragonesas, padeció una prolongada presión fiscal por parte de la monarquía desde mediados de la década de los cincuenta en el transcurso de la Guerra contra Castilla9 . Pues bien, los zaragozanos tuvieron que hacer frente en la primera mitad del año 1373 a dos compartimentos

${ }^{7}$ Juan ABELla SAMITIER, La villa aragonesa de Sos en la Baja Edad Media: economía, sociedad y manifestaciones de poder, Tesis Doctoral inédita, Zaragoza, 2007, pp. 20-32.

${ }^{8}$ Una notable excepción es el trabajo de Máximo DiAGO HERNANDO en el que analiza la hacienda de Calatayud a través de la documentación depositada en el Archivo de la Corona de Aragón. Haciendas municipales en el reino de Aragón durante el siglo XIV. El caso de Calatayud y su comunidad de aldeas, en Denis MENJOT, Manuel SÁNCHEZ MARTÍNEZ (coords.), Fiscalidad de Estado y, fiscalidad municipal en los reinos hispánicos medievales, "Collection de la Casa de Velázquez", 92, Madrid, 2006, pp. 335-356.

${ }^{9}$ Susana LOZANO GRACIA ha documentado numerosos compartimentos en Zaragoza entre los años 1362 y 1375 . La población de la ciudad de Zaragoza en los siglos XIV y, XV, en José Angel SESMA MUNOZ, Carlos LALIENA CORBERA (coords.), La población de Aragón en la Edad Media (siglos XIII-XV). Estudios de demografía histórica, Zaragoza, Grupo consolidado de investigación CEMA, Leyere Editorial, 2004, pp. 473-476. 
aprobados por sus autoridades municipales; uno de 35.000 sueldos con destino a sufragar los gastos originados por la boda del primogénito, el infante don Juan; el segundo de 15.000 sueldos, ordenado "por razon de los censsales que la ciudat devia pagar"10. En algunos albaranes de pago de las parroquias y aldeas de la ciudad, en vez de censales se habla de violarios ${ }^{11}$, pero el compartimento de 15.000 sueldos es el mismo, el establecido el 22 de febrero de ese año. Precisamente, el libro de la mayordomía que se conserva para el ejercicio 1373-1374 recoge el pago de algunas pensiones de censales y de violarios por parte del mayordomo, Juan Jiménez Sinués ${ }^{12}$, lo que confirma la existencia de una deuda pública consolidada en la ciudad de Zaragoza en los inicios de la década de los setenta, que ya era de tal magnitud que obligó a sus magistrados a poner en funcionamiento la maquinaria fiscal para recaudar una suma notable, 15.000 sueldos jaqueses, con la que pagar sus intereses.

A este respecto conviene señalar que un vaciado de los protocolos notariales de Zaragoza entre 1358 y 1365, efectuado por el doctorando Mario Lafuente, a quien agradezco su generosidad y compañerismo al proporcionarme estos datos, ha permitido localizar una serie de censales y de violarios emitidos por aljamas judías y musulmanas, y por municipios, tanto de realengo como de señorío; así, se tiene un censal vendido por la morería de Cadrete en $1350^{13}$; un violario de Mallén en $1358^{14}$; un censal de Lanaja en $1361^{15}$; un censal de los judíos de Zaragoza en $1362^{16}$; un violario de Sástago ${ }^{17}$, un censal del lugar de Sena ${ }^{18}$ y un censal de la morería de Zaragoza en $1363^{19}$; un censal de $\mathrm{Jaca}^{20}$ y un violario de los judíos de Zaragoza en $1365^{21}$; o un censal de Caspe en $1371^{22}$, por lo que parece indudable que la realidad de estos nuevos instrumentos de crédito se introdujo paulatinamente en Aragón por estas fechas ${ }^{23}$, aunque todavía falte realizar una investigación

\footnotetext{
${ }^{10}$ Archivo Histórico de Protocolos Notariales de Zaragoza (AHPZ), Gil de Borau, 1373, f. 39 (pago de los jurados y hombres buenos de La Muela del 9 de abril). abril).

${ }^{11}$ AHPZ, Gil de Borau, 1373, ff. 41 v-42 (pago de la parroquia de San Nicolás del 11 de

${ }^{12}$ Blanca FERRER PlOU, Contribución a la historia institucional de la mayordomía municipal de Zaragoza (1373-1374), Zaragoza, Institución Fernando el Católico, 1979.

${ }^{13}$ AHPZ, Domingo de Tarba, 3.820, 1350, ff. 111-118.

${ }^{14}$ AHPZ, Pedro Loarre, Leg 1, 1358, ff. 15 v-16.

${ }^{15}$ AHPZ, Blasco Aznárez de Ansó, Leg 3.887, 1361 (cuaderno 1), ff. 15-23 v.

${ }^{16}$ AHPZ, Blasco Aznárez de Ansó, Leg 3.887, 1362 (cuaderno 2), ff. 86-86 v.

${ }^{17}$ AHPZ, Pedro Martínez de Gassenat, Leg 2, 1363, f. 97 v.

${ }^{18}$ AHPZ, Blasco Aznárez de Ansó, Leg 3.887, 1362 (cuaderno 2), ff. 31-48.

${ }^{19}$ AHPZ, Pedro Martínez de Gassenat, Leg 2, 1363, f. 133 v.

${ }^{20}$ Carmen María LóPez PÉREZ, Jaca. Documentos municipales (1269-1400), "Fuentes Históricas Aragonesas", 22, Zaragoza, Institución Fernando el Católico, 1995, documentos 42-46, pp. 90-122.

${ }^{21}$ AHPZ, Gil de Borau, Registro de 1365, ff. 16 v-17.

${ }^{22}$ AHPZ, Papeles sueltos, siglo XIV.

${ }^{23}$ Las primeras referencias conocidas de emisiones de deuda pública de municipios aragoneses son las ventas de un censal de Almudévar en 1324, de otro censal de la aljama judía de Zaragoza en 1326 y de un violario del concejo de Teruel en el año 1334, aunque ello no implique que en estas tempranas fechas el sistema censal estuviese plenamente institucionalizado en los
} 
en profundidad que determine con mayor precisión la cronología de estas emisiones $^{24} \mathrm{y}$, sobre todo, las circunstancias políticas y económicas en las que se produjeron.

Otra localidad que permite profundizar en el fenómeno de la creación de una deuda pública por parte de las haciendas locales aragonesas es Calatayud. Esta ciudad, que era la segunda de mayor población del reino, padeció enormemente en la guerra contra Castilla, puesto que estuvo en primera línea de combate y fue ocupada por las tropas enemigas durante cuatro años, entre 1362 y 1366 . Muchos castillos de su comarca fueron destruidos en el transcurso del conflicto bélico, así como edificios emblemáticos de la propia ciudad, como la colegiata del Santo Sepulcro y la iglesia de Santa María de la Peña ${ }^{25}$. Es por ello que, una vez finalizada la guerra, Calatayud tuvo que hacer frente no sólo a sus deudas, sino también a un costoso proceso de reconstrucción urbana.

Es en este contexto donde se debe enmarcar el acuerdo al que llegaron en la década de los setenta la ciudad de Calatayud y el hombre de negocios de origen bearnés Juan Mercer, por el cual el municipio le cedió, posiblemente a perpetuidad, sus principales ingresos, como las primicias, los cuartos de diezmos, las corredurías y otras rentas de propios a cambio del pago de 10.000 libras jaquesas y de que el magnate les entregase 6.000 florines a varios vecinos de Barcelona para que de este modo se cancelasen las deudas contraídas con ellos por el consistorio bilbilitano ${ }^{26}$. Se aprecia pues, tanto la necesidad de numerario de la ciudad al terminar la guerra como la existencia de una deuda de cierta envergadura con ciudadanos barceloneses.

Muy pronto, las autoridades municipales de Calatayud fueron conscientes de que el pacto con Mercer era insostenible desde el punto de vista económico al dejar prácticamente sin ingresos ordinarios a sus arcas locales, por lo que desde 1379 iniciaron pleitos y acciones de diversa índole para

consistorios del país. J.V. García MARSILla, Vivir a crédito en la Valencia medieval, citado, p. 248.

${ }^{24}$ Una relación de los censales comprados por el poderoso prohombre zaragozano Beltrán Coscó en el tránsito del siglo XIV al XV evidencia cómo este instrumento crediticio se consolidó en todo el reino en la segunda mitad del Trescientos. Así, en 1387 adquirió un censal a la aljama judía de Calatayud; en 1389 a las localidades de Aranda, Botorrita, Tosos y Aguilón; en 1391 a Ayerbe, Belchite, La Puebla de Albortón, Quinto y Gelsa; en 1393 a Ejea de los Caballeros, Luco, Paniza y Aladrén; en 1397 a Fuentes de Ebro, Longares y a la aljama judía de Zaragoza; en 1401 a Mezalocha, Muel y Villafeliche; en 1403 a Sariñena y Tauste; en 1406 a Longares y a la aljama musulmana de Zaragoza; en 1407 a Argavieso, Utebo, Zuera y a la comunidad de aldeas de Daroca; en 1408 a Vera, Bulbuente Morata, Botorrita, Fuendetodos, Aguilón, Mediana, Longares, La Almunia de Doña Godina, Gotor, Morata, Villanueva, Estercuel, Gargallo, Cañizar, Ateca, Arándiga, Ansó, Fago y Ornat; en 1409 a Besimbre; y en 1410 a Alagón, Figueruelas y a la aljama judía de Jaca. Enrique MAINÉ BURGUETE, Ciudadanos honrados de Zaragoza. La oligarquía zaragozana en la Baja Edad Media (1370-1410), Zaragoza, Grupo de Investigación de Excelencia CEMA, Colección Mancuso, 4, 2006, pp. 150-151.

${ }^{25}$ Juan Fernando UTRILla UTRILLA, La población de Calatayud y su comunidad de aldeas ante la crisis demográfica del siglo XIV (1350-1414), en J.A. SESMA MUNOZ; C. LALIENA CORBERA (coords.), La población de Aragón en la Edad Media, citado, pp. 403-467.

${ }^{26}$ Máximo DiAGO HERNANDO, Los hombres de negocios bearneses en la Corona de Aragón durante la segunda mitad del siglo XIV: el ejemplo de Juan Mercer, "Aragon en la Edad Media",

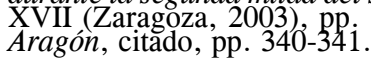


rescindir el contrato. El litigio, que enfrentaba a la segunda ciudad de Aragón contra un hombre de negocios bien colocado en el entorno regio, motivó la intervención del infante Juan, quien en el año 1381 dictó una sentencia arbitral por la que anuló la operación, obligando a los bilbilitanos a devolverle 7.000 libras al bearnés así como 22.000 sueldos por cada año en que éste no pudo disfrutar de las rentas asignadas, cancelándose también el compromiso del mercader de entregar 6.000 florines a ciudadanos de Barcelona. El propio príncipe especificó el modo en que la ciudad debía financiar esta costosa indemnización, que se hizo mediante una masiva emisión de censales y de violarios vendidos a vecinos de Zaragoza y de Barcelona, puesto que si se hubiese optado por la solución de recaudar la elevada suma mediante pechas, según la opinión del infante, se podía haber provocado la despoblación de Calatayud ${ }^{27}$.

Tras esta enorme venta de censales y de violarios, la deuda de la ciudad alcanzó límites extraordinarios, como se desprende del testimonio de sus síndicos en las Cortes de Zaragoza de 1398-1400. Según los procuradores, el consistorio debía satisfacer cada año 130.000 sueldos por los siguientes conceptos; 10.000 sueldos en pensiones y salarios de oficiales y procuradores; 10.000 sueldos en otros gastos ordinarios y extraordinarios; 2.600 sueldos en el salario de los regidores hidalgos y para que los infanzones aceptasen contribuir en las sisas; diversas cuantías para reparar muros y castillos; y la imponente cantidad de 75.000 sueldos para pagar censales. En cambio, los ingresos por sisas, aún participando en las mismas los clérigos, los hidalgos y los judíos, solamente alcanzaban los 63.000 sueldos, por lo que los síndicos bilbilitanos solicitaron al rey que les ampliase el plazo de cobro de sisas de ocho a quince años y que pudiesen incrementar las tasas para obtener por razón del impuesto 130.000 sueldos, con los que se procedería a cancelar censales. Las protestas de los representantes de los infanzones y de la comunidad de aldeas de Calatayud, que no deseaban un incremento ni del tiempo de las sisas ni de sus tasas, hicieron que el monarca dejase en manos de una comisión de las Cortes la resolución de la controversia ${ }^{28}$.

Los resultados no debieron ser los apetecidos por las autoridades bilbilitanas, puesto que tiempo después tuvieron que recurrir de nuevo a Martín I ante la imposibilidad de cumplir sus compromisos con sus acreedores censalistas, especialmente con los catalanes. Es por ello que el rey medió para que un hombre de su confianza, Joan dez Pla, doctor en leyes, comprase de sus conciudadanos barceloneses todos los censales que éstos tenían sobre

\footnotetext{
${ }^{27}$ M. DiAgo HeRnANDo, Haciendas municipales en el reino de Aragón, citado, pp. 341-342.

${ }^{28}$ Los representantes de la universidad de Calatayud habían negociado con los distintos grupos sociales su participación en las sisas durante quince años; así, para que los clérigos contribuyesen, se pagaron 800 florines al obispo de Tarazona; asimismo, se pagó por los caballeros e infanzones 1.700 florines; y con los judíos se acordó que fuesen excusados del pago de muros a cambio de participar en las sisas. Germán NAVARRO ESPINACH (ed.), Acta Curiarum Regni Aragonum. Cortes del reinado de Martín I, Tomo VI, Vol. 1, Zaragoza, Grupo de Investigación de Excelencia CEMA, Ibercaja, Cortes de Aragón y Gobierno de Aragón, 2008, pp. 316-320.
} 
Calatayud; a cambio, la ciudad le vendió las rentas municipales del almodí y las corredurías mayores y menores ${ }^{29}$.

Además de Calatayud, otras importantes localidades aragonesas padecieron crisis económicas a finales del siglo XIV por haber emitido una excesiva deuda pública a lo largo de la centuria. Entre las mismas destacó Fraga, una población que en la época contaba con unos 400 fuegos y que se caracterizó en el Trescientos por oscilar entre el señorío y el realengo. En el año 1361, su señor, el infante don Fernando, concedió indemnidad de pago al consistorio de todos los censales que el municipio había creado en el pasado (el primero del que se tiene constancia data de 1309), aunque para cancelar estos instrumentos y recuperar rentas feudales que tenía enajenadas, el infante les obligó a emitir un censal de 40.000 sueldos jaqueses de propiedad que vendieron al $6,6 \%$. Una década después, en el año 1373, la viuda de don Fernando, la infanta doña María, renunció al usufructo de las propiedades de su difunto esposo, a cambio de lo cual recibió del Ceremonioso 60.000 florines de Aragón a modo de compensación. De esa notable suma, Fraga contribuyó vendiendo censales por valor de 4.500 sueldos barceloneses de pensión anual, de los que 1.000 fueron sufragados por la comunidad musulmana de la villa ${ }^{30}$.

Estas sucesivas emisiones de deuda pública, en parte determinadas por los requerimientos de sus señores, hicieron que la situación financiera de Fraga se degradase paulatinamente. Es por ello que en el año 1391 sus autoridades llegaron a un acuerdo con cuatro de sus principales acreedores, Bertrán Navarra, Bernat Cortit, Joan de Sobirats y Bernat de Navers, ciudadanos de Lérida, para que cancelasen toda la deuda del municipio a cambio de recibir 25.000 sueldos jaqueses anuales durante dieciocho años.

En la concordia se especificaron todos los instrumentos de deuda que Fraga tenía sobre sí, lo que permite conocer con precisión la situación de su hacienda a finales del Trescientos. Así, en 1391 la villa pagaba 20.713 sueldos y 7 dineros anuales de intereses. El global de su deuda se componía de cinco préstamos de judíos con un capital total de 18.200 sueldos; de diez violarios, con un capital de 26.018 sueldos y 2 dineros, a un tipo de interés del 16,6\%, por lo que anualmente se pagaban pensiones de 3.742 sueldos y 7 dineros; $y$ finalmente 33 censales, con una propiedad global de 157.388 sueldos y unas pensiones anuales de 13.348 sueldos, al haberse suscrito la mayoría a un tipo del 8,3\%. En suma, Fraga tenía en 1391 una deuda de cerca de 200.000 sueldos, de los que un $9 \%$ se debían a judíos mediante contratos de crédito tradicionales; un $13 \%$ a poseedores de violarios; y un $78 \%$ a titulares de censales, lo que revela cómo en el último tramo del siglo XIV el censal se había impuesto con claridad sobre el resto de modalidades crediticias.

\footnotetext{
${ }^{29}$ En el año 1429 se suscitó un pleito entre Angelina, viuda de Joan dez Pla, y los oficiales y vecinos de Calatayud, que fueron acusados de boicotear el derecho de la viuda a percibir las rentas que la ciudad le había vendido a su difunto marido. M. DIAGO HERNANDO, Haciendas municipales en el reino de Aragón, citado, p. 342.

${ }^{30}$ A. Berenguer Galindo, Censal mort, citado, pp. 37-39.
} 
Pese a la concordia suscrita en 1391 con los cuatro ciudadanos de Lérida, Fraga fue incapaz de satisfacerles los 25.000 sueldos anuales acordados por sus propios medios, por lo que, de nuevo, tuvo que recurrir a la emisión de deuda pública. De esta manera, entre 1394 y 1406, Fraga vendió dieciséis censales por un valor total de 143.745 sueldos jaqueses, a un tipo medio del 7,21\%. Este nuevo incremento del número de censales obligó a la villa, ubicada en una estratégica zona, a buscar la mediación de la monarquía con sus acreedores, lo que consiguió por el interés de la Corona en el desarrollo de este enclave fronterizo entre Aragón y Cataluña. El intervencionismo regio favoreció que entre 1407 y 1418 se produjese una reducción del tipo de interés de los nuevos censales del 7,21\% al 5,12\%, a lo que se debe añadir que en 1409 expiró la obligación de los fragatinos con los cuatro poderosos capitalistas de Lérida. De este modo, las arcas locales experimentaron un indudable alivio, puesto que en el año 1418 tan sólo se tuvieron que pagar como intereses de la deuda 9.402 sueldos, muy lejos de los 20 ó 25.000 que se habían llegado a solventar décadas atrás ${ }^{31}$.

Finalmente, se debe indicar, con los datos disponibles, que los tipos de interés en la segunda mitad del siglo XIV en Aragón fueron bastante elevados, con tasas del 16,6\% para los violarios y del 8,3\% para los censales ${ }^{32}$ que, en ocasiones, sobre todo en la década de los sesenta, llegaron a alcanzar el $10 \%$, por lo que el peso de la deuda sobre los municipios fue muy notable, como testimonian casos significativos como los de Calatayud o Fraga, donde la mediación de la Corona fue decisiva para reducir la presión generada por los intereses.

\section{LAS EMISIONES DE DEUDA PÚBLICA EN EL SIGLO XV}

Como se ha dicho anteriormente, los estudios sobre haciendas municipales en el siglo XV son más abundantes y sistemáticos. Estas investigaciones muestran que en el primer tercio del Cuatrocientos, las finanzas locales aragonesas lograron, por lo general, un equilibrio entre sus ingresos y gastos, con una deuda pública notable, pero que se había reducido, tanto en volumen como en los tipos de las pensiones. El hecho de que la presión de la deuda no fuese tan agobiante como antaño, permitió a algunos municipios realizar nuevas emisiones de censales, no para pagar los intereses de la deuda consolidada o servicios a la monarquía, sino para acometer

\footnotetext{
${ }^{31}$ Ibídem, pp. 41-48.

${ }^{32}$ Además de los datos de Fraga, se dispone de los censales vendidos por los consistorios de Huesca y de Jaca en la década de los ochenta del siglo XIV a un tipo del 8,3\%. ${ }^{\mathrm{a}}$ T. IRANZO MuNío, Elites políticas y gobierno urbano, citado, p. 428. C. $\mathrm{M}^{\mathrm{a}}$ LÓPEZ PÉREZ, Jaca. Documentos municipales, citado, documento 68, pp. 169-175.

${ }^{33}$ Véase por ejemplo el censal vendido por el concejo de Sena en 1363 o el de Jaca en 1365 . AHPZ, Blasco Áznárez de Ansó, Leg 3.887, 1362 (cuaderno 2), ff. 31-48. C. M ${ }^{\mathrm{a}}$ LÓPEZ PÉREZ, Jaca. Documentos municipales, citado, documento 42, pp. 90-102.
} 
mejoras en su infraestructura urbana, conseguir mayores cuotas de autonomía o constituir señoríos en su entorno más próximo.

Esto último es lo que hizo, por ejemplo, la ciudad de Huesca, que entre 1424 y 1427 vendió tres censales por 50.600 sueldos a unos tipos de entre el 5 y el $7 \%$ para adquirir de un noble dos enclaves cercanos. Poco después emitió otro censal de 4.000 sueldos al $5 \%$ para comprar otra pequeña aldea a un infanzón. Pese a este incremento de su deuda pública, el municipio canceló progresivamente estos censales entre 1433 y 1443 , por lo que el efecto sobre sus finanzas fue muy corto en el tiempo, dejando como fruto un señorío sobre el que la ciudad pudo ejercer su autoridad y recaudar rentas de diversa naturaleza ${ }^{34}$.

Por su parte, Zaragoza, que en 1440 pagaba como intereses anuales por su deuda pública 30.978 sueldos y 4 dineros, emitió censales durante dos años que incrementaron esas pensiones en unos 3.000 sueldos. Con los capitales obtenidos, la ciudad acometió obras públicas necesarias, como la terminación del puente de piedra, la construcción de la cárcel o la compra de las tiendas de la Puerta de Toledo. Una vez finalizadas estas inversiones, el municipio redujo progresivamente su deuda cancelando censales, de tal modo que en 1456 únicamente debía sufragar 18.760 sueldos de intereses, casi la mitad que hacía quince años ${ }^{35}$.

También localidades más modestas, como Sos, recurrieron al censal para mejorar su situación, en este caso financiando la compra a la Corona en 1440 por 300 florines de oro de un privilegio por el que no habría más alcaides en su castillo, pasando a depender el mismo de sus autoridades municipales. De este modo, la villa ganó una considerable autonomía y una valiosa tranquilidad al expulsar del seno de sus murallas a miembros de la pequeña nobleza que, debido al dominio de la fortaleza, habían cometido diversos abusos y alteraciones del orden público al participar en luchas de bandos dentro del enclave cincovillés ${ }^{36}$.

Esta realidad de relativo equilibrio financiero comenzó a variar en el tránsito de la década de los cuarenta a la de los cincuenta. En efecto, si Fraga había conseguido estabilizar sus cuentas públicas con la operación de rescate de la monarquía en los primeros años del Cuatrocientos, hasta tal punto que en 1434 solamente pagó 8.281 sueldos por pensiones de censales y 666 por violarios, quince años después comenzó a emitir deuda pública abundantemen-

\footnotetext{
${ }^{34}$ Los enclaves comprados fueron Apiés y Lienas a Pedro Jiménez de Embún y Pueyo al escudero Jaime Cáncer. M ${ }^{\text {a }}$ T. IRANZO MUÑIO, Elites políticas y gobierno urbano, citado, pp.

${ }^{35} \mathrm{~B}$. PAlacios Martín; Ma I. FAlCón PÉREZ, La hacienda municipal de Zaragoza, citado, pp. 585-594.

${ }^{36} \mathrm{La}$ villa financió la adquisición del privilegio vendiendo un censal de 500 sueldos de pensión por 7.500 sueldos en el año 1441. Tres años después, en 1444, el concejo de Sos vendió otro censal, de 250 sueldos de pensión por 3.500 sueldos para destinar la suma obtenida a indemnizar a los descendientes del último alcaide del castillo. J. ABELLA SAMITIER, La villa aragonesa de Sos, citado, pp. 844-845.
} 
te. De esta manera, entre 1449 y 1461 vendió once censales por valor de 4.975 libras jaquesas, a un tipo medio de interés del $6,36 \%{ }^{37}$.

También Huesca conoció un aumento considerable de su deuda desde finales de los años cuarenta, incrementándose paulatinamente los intereses anuales que debía pagar por razón de censales desde los 3.450 sueldos de 1448 a los 5.133 de 1459 , esto es, cerca del $50 \%{ }^{38}$.

Las causas de estas nuevas emisiones de deuda por parte de los municipios aragoneses, además de puntuales malos años de cosechas en que los consistorios tuvieron que financiar mediante esta vía la compra de cereales, se debieron otra vez a las exigencias de servicios económicos por parte de la monarquía con los que sufragar las aventuras napolitanas del Magnánimo y las castellanas y navarras de su hermano don Juan. En este sentido resulta especialmente significativo que la deuda de las haciendas locales comenzase a crecer en el tránsito de los años cuarenta a los cincuenta, justamente cuando en las Cortes de Zaragoza de 1451-53 se concedió un subsidio de unos 500.000 florines de oro a diversos miembros de la casa real, destacando los 380.000 que recibió el futuro Juan II a cambio de comprometerse a respetar la tregua establecida entre Castilla y Aragón ${ }^{39}$.

Precisamente, las complicaciones que Juan II padeció en Navarra, con el inicio de la guerra civil contra el príncipe de Viana en 1451, afectaron a muchas localidades aragonesas situadas en la frontera del reino pirenaico, puesto que tuvieron que dar apoyo logístico a las tropas del rey y preparar la defensa de las propias villas, ya que las acometidas vianistas contra estas poblaciones fueron relativamente habituales. Ello motivó que estos modestos núcleos recurriesen a la emisión de censales para financiar estos gastos, siendo el origen de una deuda que devendría crónica en la segunda mitad de la centuria. Así, Uncastillo, cuya comunidad cristiana apenas llegaba a las 150 familias, suscribió censales entre 1450 y 1454 por valor de 37.000 sueldos a unos intereses muy elevados de entre el 7 y el $8 \%{ }^{40}$. Similar fue el caso de la pequeña Sádaba, que ni siquiera poseía 100 fuegos y que en 1451 y 1452 vendió dos censales al 8,3\%, por los que ingresó la suma de 15.000 sueldos $^{41}$. También Sos siguió una política semejante, alcanzando su deuda unos niveles tan preocupantes en 1456 que obligó a sus autoridades a imponer durante tres

\footnotetext{
${ }^{37}$ En 1434 el monto de las pensiones equivalía a la mitad de lo que la villa obtenía por el arriendo anual de sus pastos en los mejores años. Además, Fraga contaba con otros ingresos importantes, como la questia, la primicia, el peaje del puente y el control del abasto del vino. A. BERENGUER GALINDO, Censal mort, citado, pp. 54-56, 236.

${ }^{38} \mathrm{M}^{\mathrm{a}}$ T. IRANZO MUÑío, Élites políticas y gobierno urbano, citado, p. 429

${ }^{39}$ Luisa María SÁNCHEZ ARAgONÉs, Cortes, monarquía y ciudades en Aragón, durante el reinado de Alfonso el Magnánimo (1416-1458), Zaragoza, Institución Fernando el Católico, 1994, pp. 375-378.

${ }^{40}$ Archivo Histórico de Protocolos Notariales de Sos del Rey Católico (AHPS), Antón de Pomar, 1491-98, ff. 67-69 v.

${ }^{41}$ AHPZ, García López de Sada, 1468-69, ff. 72 v-77.
} 
años un repartimiento de 1.000 sueldos anuales para pagar las pensiones de los censales ${ }^{42}$.

A finales de la década de los cincuenta, fueron varios los municipios que, ante el tamaño de su deuda, decidieron rebajarla comprando censales a un tipo de interés más bajo para cancelar los antiguos. Es lo que intentó Huesca, debido a que en 1457 el pago de pensiones censales ya suponía un tercio de sus gastos, lográndolo en parte, puesto que consiguió atraer capitales de nuevos inversores, alguno de origen converso, como los Santángel de Barbastro, con los que pudo ejecutar esta política de reducción ${ }^{43}$. En Daroca en 1459 se aprobó un estatuto para destinar durante diez años los ingresos provenientes de sus herbajes, unos 5.000 sueldos anuales, a cancelar censales, para rebajar de este modo el coste del pago de sus intereses, que en esa época era de unos 10.000 sueldos $^{44}$.

No obstante, toda esta tendencia al saneamiento de la deuda se quebró al iniciarse la Guerra de Cataluña en 1462. La necesidad de apoyo económico por parte de la monarquía fue imperiosa, puesto que lo que estaba realmente en juego era la supervivencia de la propia estructura de la Corona de Aragón. Es por ello que los requerimientos a los aragoneses fueron continuos y muy elevados, lo que obligó a sus consistorios a aumentar su partida de gastos. Al mismo tiempo, varias localidades, sobre todo las más cercanas al Principado y las que más relaciones económicas tenían con el territorio catalán, sufrieron un descenso importante de sus ingresos, como por ejemplo Fraga, puesto que ante el riesgo de verse afectada directamente por la guerra, no encontró quien comprase sus yerbas, con lo que uno de los pilares de su hacienda se devaluó notablemente ${ }^{45}$, contribuyendo a acrecentar, aún más si cabe, el desequilibrio entre las entradas y las salidas de sus arcas, por lo que el recurso al endeudamiento fue inevitable.

Las cifras que se tienen para el periodo 1462-1472 son muy elocuentes para ilustrar las masivas emisiones de censales que protagonizaron los municipios aragoneses. Así, en esta década Fraga vendió siete censales por valor de 1.671 libras jaquesas, a un tipo medio del $7,11 \%$, aunque hubo casos de instrumentos suscritos al 8,3\%, al 9,8\% e inclusive al 10\% ${ }^{46}$. También en Huesca el crecimiento de la deuda fue exponencial, puesto que si en 1461 pagaba 5.483 sueldos en concepto de pensiones censales, en 1484, primer ejercicio tras la guerra del que se tienen datos, esta cantidad se había duplicado, situándose cerca de los 11.000 sueldos anuales, constatándose igualmente un aumento de los tipos, ya que si a comienzos del siglo XV el

\footnotetext{
${ }^{42}$ Además se estableció que durante un sexenio las rentas de la primicia, de los herbajes, de los hornos y de los molinos se destinasen prioritariamente al pago de los intereses de los censales, de las caballerías y de los salarios de los abogados de la villa. J. ABELLA SAMITIER, La villa aragonesa de Sos, citado, pp. 845-846.

${ }^{43} \mathrm{M}^{\mathrm{a}}$ T. IRANZO MUÑ̃́o, Élites políticas y gobierno urbano, citado, p. 430. 287.

${ }^{44} \mathrm{M}^{\mathrm{a}}$ L. Rodrigo ESTEVAN, Poder y vida cotidiana en una ciudad bajomedieval, citado, $\mathrm{p}$.

${ }^{45}$ A. Berenguer Galindo, Censal mort, citado, p. 57.

${ }^{46}$ Ibídem, pp. 56-59, 236.
} 
predominante era el $5 \%$, en los años de la guerra ascendió en la ciudad oscense hasta el 6,6\%, llegándose a veces a triplicar este interés en contratos establecidos a muy corto plazo ${ }^{47}$. En la capital del reino se ha documentado que entre 1468 y 1472 el consistorio zaragozano vendió censales por 183.000 sueldos de propiedad y unos 12.500 de pensión, siendo el tipo predominante el $6,6 \%$, aunque también se han localizado modalidades de intereses superiores, de hasta el $15,7 \%$, e inferiores, del 5 e inclusive del $4,8 \%{ }^{48}$. En cuanto a Daroca, se sabe que en el año 1473 debía destinar unos 12.000 sueldos al pago de su deuda, lo que representaba un $36 \%$ de todos sus gastos $^{49}$.

De esta manera, al terminar la guerra, la situación de la mayoría de los municipios aragoneses, desde el punto de vista financiero, era calamitosa y en algunos casos cercana a la quiebra, con consistorios que dedicaban a la satisfacción de los intereses de su deuda entre un tercio y la mitad de sus gastos, mientras que otros, ante la imposibilidad de hacer frente a sus obligaciones, vieron cómo sus rentas eran secuestradas por la corte del Justicia de Aragón y entregadas a sus acreedores, caso de la villa de Uncastillo y sus censalistas zaragozanos $^{50}$. En otras ocasiones la única solución que encontraron los regidores locales fue una huida hacia delante consistente en emitir más censales para cubrir el déficit, como ejemplifica Fraga, que entre 1473 y 1489 vendió quince censales a un tipo medio del $5,75 \%$ con los que obtuvo 7.128 libras jaquesas ${ }^{51}$.

A la elevada cuantía de la deuda global de cada enclave ha de añadirse el hecho de que la mayor parte de censales se habían suscrito a unos tipos muy altos, generados por la coyuntura bélica. Es por ello que los planes de saneamiento finiseculares de las ciudades y villas tuvieron dos objetivos complementarios; por un lado, reducir la deuda y por otro, cuando esto no fue posible, negociar una reducción de los intereses para ubicarlos en torno al $5 \%$, siguiendo en gran medida el modelo impuesto por Fernando el Católico en el salvamento de la hacienda del General de Aragón ${ }^{52}$.

Es lo que acaeció en Huesca, donde entre 1496 y 1497 se cancelaron préstamos por importe de 65.500 sueldos, amortizaciones que se nutrieron de los capitales aportados por nuevos censales contratados a un interés mucho menor que los antiguos, al 5\%. Igualmente se sabe que las autoridades

\footnotetext{
${ }^{47} \mathrm{M}^{\mathrm{a}} \mathrm{T}$. IRANZO MUÑío, Élites políticas y gobierno urbano, citado, pp. 429-430.

${ }^{48} \mathrm{~B}$. PALACIOS MARTíN; M ${ }^{\mathrm{a}}$ I. FAlCón PÉREZ, La hacienda municipal de Zaragoza, citado, pp. $588-589$.

${ }^{49}$ José Luis CORRAL LAFUENTE, La ciudad de Daroca según el libro de actas de 1473, “Aragón en la Edad Media”, IV (Zaragoza, 1981), pp. 184-186.

${ }^{50}$ En el año 1475 un grupo de habitantes de la villa de Uncastillo nombró procuradores para arrendar de don Pedro de Francia, de don Ximeno Gordo y de don micer Juan de Santángel, ciudadanos de Zaragoza y acreedores de los hombres de signo y de servicio de la localidad cincovillesa, las rentas que les tenían secuestradas. AHPS, Juan Coscón, 1475, f. 11r.

${ }^{51}$ A. Berenguer GaLindo, Censal mort, citado, p. 236.

${ }^{52}$ Sobre la reforma de la hacienda del reino que protagonizó Fernando el Católico, véase José Ángel SESMA MUÑOZ, La Diputación del reino de Aragón en la época de Fernando II, Zaragoza, Institución Fernando el Católico, 1977, pp. 179-243.
} 
oscenses negociaron con algunos de sus grandes prestamistas unas condiciones más benignas e incluso plazos para luir progresivamente su deuda. Es interesante señalar cómo los nuevos capitalistas y los prestamistas antiguos más proclives a colaborar fueron personas del entorno del rey, lo que induce a pensar en una mediación del monarca, máxime cuando las soluciones del consistorio oscense fueron idénticas a las aplicadas por el Católico en la Diputación $^{53}$.

Por otra parte, en Daroca, gracias a los esfuerzos contributivos de sus vecinos, se logró que la cantidad destinada al pago de los intereses de su deuda pública pasara de los 12.000 sueldos anuales de 1473 al terminar la guerra a los 6.500 ó 7.000 de la década de los ochenta ${ }^{54}$.

Más dificultades tuvieron los dirigentes fragatinos para salvar su hacienda local. Así, en 1490 suscribieron un acuerdo con sus principales acreedores por el que los capitalistas obtuvieron durante una década el arrendamiento de la práctica totalidad de los ingresos de la villa, a cambio de pagar al resto de censalistas sus pensiones por la mitad de su valor y de comprometerse a cancelar censales para contratar otros de menor tipo. Aunque la concordia fue supervisada por el arzobispo de Zaragoza, auténtico alter ego del rey en Aragón, a través de su enviado, don Juan de Exea, muy pronto surgieron desavenencias entre las partes, ya que los arrendadores pretendían reducir tan sólo en un $25 \%$ las pensiones, mientras que las autoridades públicas exigieron que llegasen hasta el $50 \%{ }^{55}$.

En los inicios del siglo XVI, Fraga solicitó permiso al arzobispo para cancelar censales y sustituirlos por otros de menor interés, emprendiendo gestiones para encontrar capitales al 5\% en Zaragoza, lo que consiguió al vender cinco censales por 2.400 libras jaquesas al 4,76\% entre 1501 y $1506^{56}$.

La política de la Corona, proclive a la localidad fragatina, favoreció que en el año 1506 el arzobispo dictase una sentencia arbitral para dejar zanjadas las diferencias entre el consistorio y sus acreedores en torno a cuánto se debían rebajar las pensiones de sus censales. El arzobispo ordenó que los censales viejos, suscritos antes de las Cortes de Teruel, se pagasen al 2,5\%, mientras que los nuevos recibirían un interés del 5\%; asimismo, decretó que el concejo no se cargase con más instrumentos crediticios. Los resultados de estas políticas se hicieron notar enseguida, puesto que si en el año 1499 Fraga pagaba unos 27.000 sueldos de intereses, lo que consumía prácticamente todas

\footnotetext{
${ }^{53}$ Por ejemplo, Juan de Coloma, secrețario y hombre de confianza del monarca, compró un censal de 31.500 sueldos al concejo a un tipo de interés del $5 \%$, lo que permitió a los munícipes cancelar censales antiguos de unos tipos más elevados. Los magistrados oscenses también alcanzaron un acuerdo con los herederos de uno de sus mayores prestamistas, Alfonso Cortés, un clérigo, que había servido al rey, para amortizar sucesivamente sus censales. M $^{\mathrm{a}} \mathrm{T}$. IRANZO MuÑío, Elites políticas y gobierno urbano, citado, pp. 431-432. 287.

${ }^{54} \mathrm{M}^{\mathrm{a}}$ L. Rodrigo ESTEVAn, Poder y vida cotidiana en una ciudad bajomedieval, citado, $\mathrm{p}$.

${ }^{55}$ Entre los arrendatarios de las rentas durante una década sobresalió el magnífico Miguel Juan Carvi. A. BERENGUER GALINDO, Censal mort, citado, pp. 60-62.

${ }^{56}$ Ibídem, p. 236.
} 
sus rentas, en 1506 esta partida presupuestaria se redujo un $40 \%$, pese a lo cual todavía suponía tres cuartas partes de sus ingresos ${ }^{57}$.

Muchos más apuros padecieron las pequeñas villas, puesto que no contaron con el apoyo de la Corona para renegociar sus deudas, teniendo que recurrir en exclusividad a sus propios medios. Así, una vez terminada la Guerra de Cataluña, en el año 1475 los oficiales de Sos suscribieron una concordia con un prohombre local, Martín de Ampiedes, para que durante una década cancelase 12.000 sueldos censales y pagase sus pensiones correspondientes, a cambio de lo cual recibió durante ese tiempo las rentas de la primicia y de los molinos ${ }^{58}$. Similar debió de ser el acuerdo alcanzado en el año 1476 entre el consistorio de Sádaba y el notable Antón de Borau para que éste quitase los censales de la villa ${ }^{59}$, lo cual no significó la solución definitiva para las arcas municipales, ya que el 10 de enero de 1490 en una reunión del concejo se decidió cancelar durante doce años 36.000 sueldos censales, a razón de 3.000 sueldos anuales, recaudándose en cada anualidad 592 sueldos de las rentas concejiles de la primicia y de la carnicería, y los 2.408 sueldos restantes mediante repartimientos entre los vecinos ${ }^{60}$. Por su parte, la situación de Uncastillo fue dramática, ya que en 1495 tenía cargados ocho censales cuyas pensiones ascendían a 5.500 sueldos, por lo que suscribió un contrato con dos prohombres, el escudero Juan Remírez y el notario Antón de Pomar, para que éstos cancelasen progresivamente la deuda, a cambio de concederles casi todas las rentas de la villa durante un periodo muy amplio de treinta años ${ }^{61}$.

De este modo, en el tránsito del siglo XV al XVI, las poblaciones aragonesas, grandes, medianas y pequeñas, tomaron diversas medidas para reducir su deuda y los tipos de los censales que tenían contraídos desde tiempo atrás. Las investigaciones efectuadas evidencian que la deuda pública local disminuyó significativamente y que en Aragón los intereses se situaron en torno al 5\%, como se aprecia en las nuevas emisiones de censales realizadas en los inicios del Quinientos por la Diputación ${ }^{62}$ y por los concejos de

\footnotetext{
${ }^{57}$ Ibídem, pp. 63-66.

${ }^{58} \mathrm{El}$ acuerdo no llegó a cumplimentarse totalmente debido a las diferencias surgidas en los pagos entre Martín de Ampiedes, su heredero y el consistorio, cancelándose tan sólo 2.000 de los 12.000 sueldos censales previstos en la concordia. J. ABELLA SAMITIER, La villa aragonesa de Sos, pp. 847-849.

${ }^{59} \mathrm{El} 12$ de septiembre de 1476, Antón de Borau, quitador qui es de los censales de la dita villa de Sadaba, acogió en el quitamiento al también vecino de Sádâba, Martín de Busal, mencionándose que la concordia original con la villa se firmó el 18 de agosto de ese mismo año, acuerdo que lamentablemente no se ha conservado en la documentación local. AHPS, Ximeno de Busal, 1476, f. 37 .

${ }^{60}$ AHPS, Ximeno de Busal, 1490, ff. 2-3 v. En el año 1498 la villa arrendó la primicia durante siete años a Sancho de Misanz, notario y ciudadano de Zaragoza, quien se comprometió a cancelar durante los primeros cuatro años 6.500 sueldos censales que Sadaba aún debía. AHPS, Ximeno de Busal menor de días, 1498-99, fff. 3 v-4 v.

${ }^{61}$ AHPS, Sancho Pérez del Frago, 1489-95, sin foliar.

${ }^{62}$ Desde el año 1500 el tipo preponderante de los censales emitidos por la Diputación fue del $5 \%$. J. A. SESMA MuÑoZ, La Diputación del reino de Aragón, citado, p. 135.
} 
Huesca $^{63}$, Fraga $^{64}$, Sos $^{65}$ o Uncastillo ${ }^{66}$ para comprar grano en una época de carestías y para fortificar la frontera con Navarra en el momento de su conquista.

\section{CONCLUSIONES}

Como recapitulación a todo lo expuesto, pueden señalarse algunas conclusiones. La primera es la necesidad de aumentar nuestro conocimiento sobre las haciendas aragonesas en la Baja Edad Media, para lo cual resulta imprescindible utilizar de forma conjunta la documentación local con la depositada en el Archivo de la Corona de Aragón, para así tener una visión más global y contextualizada, y para disponer de datos de épocas, como el siglo XIV, de las que se sufre una carencia documental notable en los archivos municipales.

La segunda conclusión radica en que, según las investigaciones realizadas hasta el momento, se aprecia una cronología coincidente en las emisiones masivas de deuda pública efectuadas por las diferentes villas y ciudades, en la evolución más o menos generalizada de los tipos de interés e inclusive en los tiempos de dificultades, quiebras y bancarrotas.

Todo ello se debe a la estrecha relación existente entre los procesos de creación de deuda pública y las exigencias económicas de la monarquía, ya que cuando estas últimas se acrecentaron, el recurso a la emisión de censales se multiplicó. Estos lazos entre la Corona y el endeudamiento de las localidades se manifestaron igualmente en la intervención de los reyes y de su entorno en los planes de saneamiento de las finanzas de muchas poblaciones, mediando entre sus autoridades y sus acreedores para que éstos redujesen las pensiones de sus censales.

Aunque es evidente que existió una cronología similar en estos fenómenos de endeudamiento, también es cierto que cada consistorio tuvo sus propias circunstancias, siendo en este sentido esencial analizar las bases financieras de cada enclave, desde sus bienes de propios al control sobre rentas e impuestos, ya que esta realidad determinó en gran medida su mayor o menor dependencia de los diversos instrumentos crediticios. Y es que, pese a que el endeudamiento fue generalizado en los municipios aragoneses, hubo diferencias de grado, ya que mientras algunas poblaciones se vieron asfixiadas pero consiguieron sanear sus finanzas, otras llegaron a perder completamente

\footnotetext{
${ }^{63}$ En el año 1503 Huesca vendió 28.000 sueldos censales al 4,6\% para hacer frente a problemas frumentarios. $\mathrm{M}^{\mathrm{a}}$ T. IRANZO MUNíi, Elites políticas y gobierno urbano, citado, pp.

${ }^{64}$ Entre los años 1501 y 1506 Fraga vendió cinco censales a un rédito medio del 4,76\%. A. BERENGUER GALINDO, Censal mort, citado, p. 63.

${ }^{65}$ En los años 1509, 1512 y 1513 Sos vendió tres censales al 5\%. J. Abella SAMitier, La villa aragonesa de Sos, citado, p. 856.

${ }^{66}$ En el año 1512 Uncastillo vendió un censal de 2.000 sueldos al $5 \%$ para fortificar sus murallas. AHPS, Sancho Pérez del Frago, 1511-13, ff. 53-55.
} 
el dominio sobre sus rentas y bienes durante décadas a manos de sus censalistas.

\section{APÉNDICE}

LA DEUDA PÚBLICA DE LOS MUNICIPIOS ARAGONESES EN EL SIGLO XIV

\begin{tabular}{|c|c|c|c|c|}
\hline AÑOS & ZARAGOZA & CALATAYUD & FRAGA & $\begin{array}{l}\text { OTRAS } \\
\text { POBLACIONES }\end{array}$ \\
\hline $1350-65$ & $\begin{array}{l}\text { 1362.Censal ju- } \\
\text { díos. } \\
1363 \text {. Censal mu- } \\
\text { sulmanes } \\
1365 \text {. Violario } \\
\text { judíos }\end{array}$ & & $\begin{array}{l}\text { 1361. Censal de } \\
40.000 \text { s.j. al } \\
6,6 \%\end{array}$ & $\begin{array}{l}\text { 1350. Censal } \\
\text { morería Cadrete. } \\
\text { 1358. Violario } \\
\text { Mallén } \\
\text { 1361. Censal } \\
\text { Lanaja } \\
1363 \text {. Violario } \\
\text { Sástago y censal } \\
\text { Sena } \\
\text { 1365. Censal } \\
\text { Jaca }\end{array}$ \\
\hline $1370-79$ & $\begin{array}{l}\text { 1373. Comparti- } \\
\text { mento de } 15.000 \\
\text { s.j., para pagar } \\
\text { censales y viola- } \\
\text { rios }\end{array}$ & $\begin{array}{l}\text { Años } 70 . \text { Deuda de } \\
6.000 \text { fl., con barce- } \\
\text { loneses. Reciben } \\
10.000 \text { lb.j., de Juan } \\
\text { Mercer. }\end{array}$ & $\begin{array}{l}\text { 1371. Venta de } \\
\text { censales y viola- } \\
\text { rios por } 4.500 \\
\text { s.b., de pensión } \\
\text { (1.000 asumidos } \\
\text { por la morería) }\end{array}$ & $\begin{array}{l}\text { 1371. Censal de } \\
\text { Caspe }\end{array}$ \\
\hline $1380-91$ & & $\begin{array}{l}\text { 1381. Emisión de } \\
\text { deuda para pagar } \\
7.000 \text { lb.j. }\end{array}$ & $\begin{array}{l}\text { 1391. Deuda de } \\
200.000 \mathrm{~s} . \mathrm{j} . \text {. } \\
\text { Concordia con } \\
\text { censalistas para } \\
\text { cancelarla a cam- } \\
\text { bio de } 25.000 \mathrm{~s} . \mathrm{j} \text {. } \\
\text { anuales durante } \\
18 \text { años }\end{array}$ & \\
\hline $1392-1406$ & & $\begin{array}{l}\text { 1398. Se pagan } \\
75.000 \text { s.j. de pen- } \\
\text { siones }\end{array}$ & $\begin{array}{l}\text { 1394-1406. Venta } \\
\text { de } 16 \text { censales } \\
\text { por } 145.000 \mathrm{~s} . \mathrm{j} . \\
\text { al } 7,2 \%\end{array}$ & \\
\hline
\end{tabular}




\section{LA DEUDA PÚBLICA DE LOS MUNICIPIOS ARAGONESES EN EL SIGLO XV}

\begin{tabular}{|c|c|c|c|c|c|}
\hline AÑos & ZARAGOZA & HUESCA & FRAGA & DAROCA & $\begin{array}{l}\text { OTRAS POBLA- } \\
\text { CIONES }\end{array}$ \\
\hline $1407-18$ & & & $\begin{array}{l}\text { Reducción de censa- } \\
\text { les al } 5,12 \% \text {. } \\
\text { En } 1418 \text {, se pagan } \\
9.400 \text { s.j., de pen- } \\
\text { siones }\end{array}$ & & \\
\hline $1420-30$ & & $\begin{array}{l}\text { Venta de } 4 \text { cen- } \\
\text { sales por } \\
55.000 \text { s.j. en- } \\
\text { tre } 5-7 \%\end{array}$ & & & \\
\hline $1440-48$ & $\begin{array}{l}\text { 1440-42. Venta } \\
\text { de censales por } \\
3.000 \mathrm{~s} . \mathrm{j} \text {. de } \\
\text { pensión }\end{array}$ & & & & $\begin{array}{l}\text { Sos vende un } \\
\text { censal de } 7.500 \\
\text { s.j., al } 6,6 \% \text { en } \\
1441 \text { y un cen- } \\
\text { sal de } 3.500 \\
\text { s.j. al } 7,1 \% \text { en } \\
1444 \text {. }\end{array}$ \\
\hline $1449-61$ & & $\begin{array}{l}\text { Pensiones au- } \\
\text { mentan de } \\
3.500 \text { a } 5.500 \\
\text { s.j. }\end{array}$ & $\begin{array}{l}\text { Venta de } 11 \text { censa- } \\
\text { les por } 4.975 \mathrm{lb} . \mathrm{j} \text {., } \\
\text { al } 6,3 \%\end{array}$ & $\begin{array}{l}\text { 1459. Pagan } \\
10.000 \mathrm{~s} . \mathrm{j} . \text {, de } \\
\text { pensiones }\end{array}$ & $\begin{array}{l}\text { 1450-54. Un- } \\
\text { castillo vende } \\
\text { dos censales } \\
\text { por } 37.000 \text { s.j. } \\
\text { entre } 7-8 \% \text {. } \\
1451-52 . \text { Sáda- } \\
\text { ba vende dos } \\
\text { censales por } \\
15.000 \text { s.j., al } \\
8,3 \%\end{array}$ \\
\hline $1462-72$ & $\begin{array}{l}\text { 1468-72. Venta } \\
\text { de censales por } \\
183.000 \text { s.j., al } \\
6,6 \%\end{array}$ & $\begin{array}{l}\text { Censales vendi- } \\
\text { dos al } 6,6 \%\end{array}$ & $\begin{array}{l}\text { Venta de } 7 \text { censales } \\
\text { por } 1.671 \mathrm{lb} . \mathrm{j} . \text {, al } \\
7,11 \%\end{array}$ & & \\
\hline $1473-89$ & & $\begin{array}{l}\text { 1484. Las pen- } \\
\text { siones ascien- } \\
\text { den a } 11.000 \\
\text { s.j. }\end{array}$ & $\begin{array}{l}\text { Venta de } 15 \text { censa- } \\
\text { les por } 7.128 \mathrm{lb} . \mathrm{j} \text {., } \\
\text { al } 5,75 \%\end{array}$ & $\begin{array}{l}1473.12 .000 \\
\text { s.j., de pensio- } \\
\text { nes. } \\
\text { Años } 80 \text {, des- } \\
\text { ciende a } 6.500- \\
7.000 \mathrm{s.j} \text {. }\end{array}$ & $\begin{array}{l}\text { 1475. Acuerdo } \\
\text { de Sos con un } \\
\text { notable para } \\
\text { cancelar } \\
12.000 \mathrm{~s} . \mathrm{j} . \text {, } \\
\text { censales. } \\
1476 . \text { Acuerdo } \\
\text { de Sádaba con } \\
\text { un prohombre } \\
\text { para luir censa- } \\
\text { les. }\end{array}$ \\
\hline
\end{tabular}




\begin{tabular}{|c|c|c|c|}
\hline $\begin{array}{l}1490- \\
1500\end{array}$ & $\begin{array}{l}1496-97 \text { se } \\
\text { amortizan } \\
65.500 \text { s.j. de } \\
\text { deuda. } \\
\text { Nuevos censales } \\
\text { contratados al } \\
5 \%\end{array}$ & $\begin{array}{l}\text { 1490. Concordia } \\
\text { con censalistas para } \\
\text { cancelar deuda a } \\
\text { cambio de cederles } \\
\text { rentas concejiles por } \\
\text { una década. } \\
1499 \text {. Pagan } 27.000 \\
\text { s.j. como pensiones } \\
\text { anuales. }\end{array}$ & $\begin{array}{l}\text { 1490. Plan del } \\
\text { consistorio de } \\
\text { Sádaba para } \\
\text { cancelar } \\
36.000 \mathrm{~s} . \mathrm{j} . \text {., } \\
\text { censales en } \\
\text { doce años. } \\
1495 \text {. Uncasti- } \\
\text { llo paga } 5.500 \\
\text { s.j. de pensio- } \\
\text { nes. Acuerda } \\
\text { con dos nota- } \\
\text { bles que cance- } \\
\text { len los censales } \\
\text { a cambio de las } \\
\text { rentas de la } \\
\text { villa por treinta } \\
\text { años. }\end{array}$ \\
\hline $1501-16$ & $\begin{array}{l}\text { Emisiones al } \\
4,6 \%\end{array}$ & $\begin{array}{l}1501-05 \text {. } \\
\text { Venta de } 5 \text { censales } \\
\text { por } 2.400 \mathrm{lb} . \mathrm{j} ., \text { al } \\
4,76 \% \\
1506 . \text { Sentencia ar- } \\
\text { bitral reduce pensio- } \\
\text { nes al } 2,5 \text { y al } 5 \% \text {. } \\
\text { La deuda se reduce } \\
\text { un } 40 \%\end{array}$ & $\begin{array}{l}\text { Sos y Uncasti- } \\
\text { llo emiten cen- } \\
\text { sales al 5\% }\end{array}$ \\
\hline
\end{tabular}

Abreviaturas de las tablas: $\mathrm{lb} . \mathrm{j}=$ libras jaquesas; $\mathrm{s} . \mathrm{j}=$ sueldos jaqueses; $\mathrm{s} . \mathrm{b} .=$ sueldos barceloneses; $\mathrm{fl}=\mathrm{florines}$.

Fecha de recepción del artículo: noviembre 2008.

Fecha de aceptación y versión final: febrero 2009. 